\title{
Synthesis and Characterization of Nickel Doped Urea Thiourea Naphthylamine Single Crystal Developed by Slow Evaporation Method
}

\author{
B. SENTHILKUMARAN ${ }^{1}$, S. ARIVOLI ${ }^{2 *}$ and G. THANAPATHY ${ }^{3}$ \\ ${ }^{1}$ Department of Physics, Dharmapuram Adhinam Arts College, \\ Dharmapuram, Mayiladudurai, India \\ ${ }^{2}$ Department of Chemistry, Thiru Vi Ka Government Arts College, Thiruvarur, India \\ ${ }^{3}$ Department of Physics, Poompuhar College, Sirkali, India \\ arivu6363@gmail.com
}

Received 3 January 2017 / Accepted 20 January 2017

\begin{abstract}
A single crystal of nickel doped urea thiourea naphthylamine has been grown successfully from its aqueous solution. The grown crystals have been subjected to X-ray diffraction studies to identify the morphology and structure. The TGA studies showed the thermal properties of the crystals. The functional group of the grown crystals was identified by UV-Visible double beam spectra, FT-IR analysis, NMR and XRD studies.
\end{abstract}

Keywords: Urea, Thiourea, Naphthylamine, Nickel Sulphate, Nickel Naphthylamine Thiourea Urea single Crystal, X-Ray diffraction

\section{Introduction}

Crystals are the essential pillars of modern technology. Without crystals, there would be no electronic and photonic industry, fibre optical communications, which depend on crystals such as semiconductors, superconductors, polarizers, transducers, radiation detectors, ultrasonic amplifiers, ferrites, magnetic garnets, solid state lasers, non-linear optics, electrooptic, acousto-optic, photosensitive, refractory of different grades, crystalline films for microelectronics and computer industries. Crystal growth is an interdisciplinary subject covering physics, chemistry, material science, chemical engineering, metallurgy, crystallography, mineralogy, etc. In the past few decades, there has been a growing interest on crystal growth processes, particularly in view of the increasing demand of materials for technological applications ${ }^{1-10}$. Atomic arrays that are periodic in three dimensions, with repeated distances are called single crystals. It is clearly more difficult to prepare single crystal than poly-crystalline material and extra effort is justified because of the outstanding 
advantages of single crystals ${ }^{2}$. The reason for growing single crystals is, many physical properties of solids are obscured or complicated by the effect of grain boundaries. The chief advantages are the anisotropy, uniformity of composition and the absence of boundaries between individual grains, which are inevitably present in polycrystalline materials. The strong influence of single crystals in the present day technology is evident from the recent advancements in the above mentioned fields. Hence, in order to achieve high performance from the device, good quality single crystals are needed. Growth of single crystals and their characterization towards device fabrication have assumed great impetus due to their importance for both academic as well as applied research.To enable a material to be potentially useful for NLO applications, the material should be available in bulk single crystal form ${ }^{9}$. So, crystal growth of new nonlinear optical materials and investigation into their properties has become most indispensable and efficacious disciplines in the field of materials science and engineering. The rapid development of optical communication system has led to a demand for Nonlinear Optical (NLO) materials of high performance for use as components in optical devices. NLO materials are used in frequency conversion, which is a popular technique for extending the useful wavelength range of lasers. The search for new materials has identified novel semi organic systems of considerable potential and high performance ${ }^{10-21}$. There are three major stages involved in this research. The first is the production of pure materials and improved equipment associated with the preparation of these materials. The second is the production of single crystals first in the laboratory and then extending it to commercial production. The third is the characterization and utilization of these crystals in devices. In this paper, the method of crystal growth with emphasis on low temperature solution growth technique was described.

\section{Experimental}

An essential prerequisite for success in crystal growth is the availability of material of the highest purity. Solute and solvents of high purity are required, since impurity may be incorporated into the crystal lattice resulting in the formation of flaws and defects. Sometimes impurities may slow down the crystallization process by being adsorbed on the growing face of the crystal, which changes the crystal habit. A careful repetitive use of standard purification methods of recrystallization followed by filtration of the solution would increase the level of purity.

\section{Seed preparation}

$0.80 \mathrm{~g}$ of urea, $1.15 \mathrm{~g}$ of naphthylamine, $0.9 \mathrm{~g}$ of thiourea and $1.08 \mathrm{~g}$ of nickel sulphate were dissolved in $30 \mathrm{~mL}$ of double distilled water. The solution was thoroughly mixed using a magnetic stirrer. A crystalline substance was formed. The urea, thiourea, naphthylamine, nickel sulphate solution were prepared in water and maintained at $30{ }^{\circ} \mathrm{C}$ with continuous stirring to ensure homogeneous temperature and concentration. The solution was kept at $30{ }^{\circ} \mathrm{C}$ for ten days in order to get the nickel doped naphthylamine thiourea and urea doped single crystal.

Crystal growth of large single crystals can be grown from slow evaporation solution growth. Single crystals of nickel doped naphthylamine thiourea and urea are grown by slow evaporation of the saturated aqueous solution at room temperature. Good quality single crystals were grown within ten days (Figure 1).

$\mathrm{NiSO}_{4}+\mathrm{NH}_{2} \mathrm{CONH}_{2}+\mathrm{NH}_{2} \mathrm{CSNH}_{2}+\mathrm{C}_{10} \mathrm{H}_{7} \mathrm{NH}_{2} \longrightarrow \mathrm{NiNHCSNH}_{2} \cdot \mathrm{NHCONH}_{2} \cdot \mathrm{NHC}_{10} \mathrm{H}_{7}+\mathrm{H}_{2} \mathrm{SO}_{4}$ 


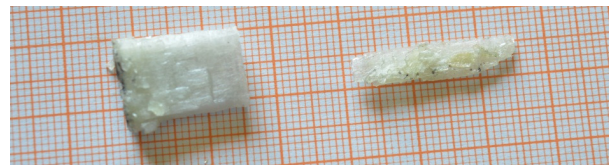

Figure 1. Photograph of NiNTU

\section{Results and Discussion}

\section{$X$-Ray diffraction analysis}

Single crystal X-ray diffraction study was performed for the grown NiNTU crystal. It was found that NiNTU crystal belongs to orthorhombic system $\left(\alpha=\beta=\gamma=90^{\circ}\right)$. Lattice parameter values of NiNTU are compared with reported NTU in Table 1. In the case of doped sample, a slight variation in the cell parameters is observed, which may be due to the incorporation of urea and thiourea ligands. This analysis reveals that the induction of urea and thiourea ligand in the NiNTU crystal does not change the crystal system though there is a small change in the lattice parameters. The powder sample of NiNTU was scanned over the range $10-80^{\circ}$ at a rate of $1^{\circ}$ per minute and the powder X-ray diffraction patterns were indexed using Check cell software (Figure 2). The lattice parameter (a) was calculated by selecting the (102) plane using the formula ${ }^{2}$ :

$$
\operatorname{Sin}^{2} \theta=\frac{\lambda^{2}}{4 a^{2}}\left(h^{2}+k^{2}+l^{2}\right)
$$

Table 1. Lattice parameter values of NiNTU and reported NTU crystals

\begin{tabular}{|c|c|c|c|c|c|c|}
\hline \multirow{2}{*}{ Sample } & \multirow{2}{*}{ System } & \multirow{2}{*}{$2 \theta$ (degree) } & \multirow{2}{*}{ FWHM } & \multirow{2}{*}{ hkl } & \multicolumn{2}{|c|}{ Lattice parameter $(\AA)$} \\
\hline & & & & & Calculated & Reference[2] \\
\hline \multirow{3}{*}{ NTU } & \multirow{3}{*}{ Orthorhombic } & 23.25 & 0.16 & 200 & 7.644 & 7.644 \\
\hline & & 20.81 & 0.16 & 020 & 8.527 & 8.559 \\
\hline & & 32.57 & 0.24 & 002 & 5.493 & 5.492 \\
\hline \multirow{3}{*}{ NiNTU } & \multirow{3}{*}{ Orthorhombic } & 28.6258 & 0.4040 & 200 & 3.1158 & 3.2041 \\
\hline & & 20.616 & 0.4326 & 020 & 4.3046 & 4.3028 \\
\hline & & 22.9938 & 0.4553 & 002 & 3.8647 & 3.9865 \\
\hline
\end{tabular}

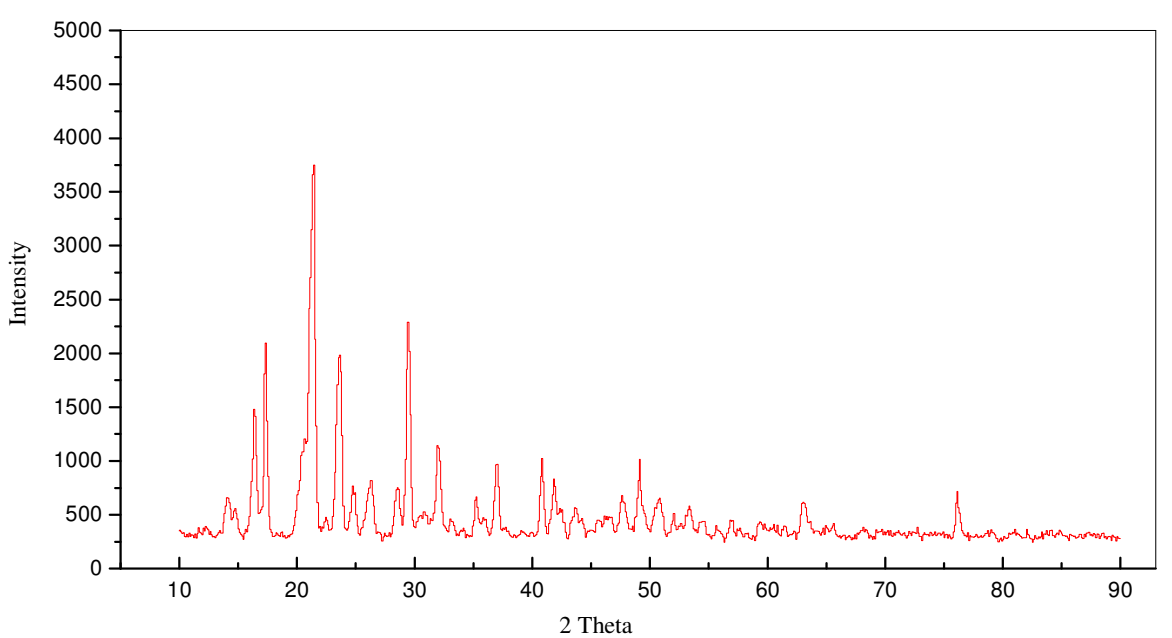

Figure 2. XRD pattern of NiNTU 


\section{Fourier transforms infrared spectroscopy}

The FT-IR spectra of nickel urea thiourea naphthylamine grown crystals are shown in Figure 3. In the higher wavelength region, the peak at 3500 is assigned to hydrogen bonding, the peak at $3480 \mathrm{~cm}^{-1}$ is assigned to $\mathrm{C}-\mathrm{H}, \mathrm{N}-\mathrm{H}$ stretching vibration. The region $3430 \mathrm{~cm}^{-1}$ and $3120 \mathrm{~cm}^{-1}$ with strong intensity represents $\mathrm{N}-\mathrm{H}$ stretching mode. The broad envelope positioned in between $3420 \mathrm{~cm}^{-1}$ and $2740 \mathrm{~cm}^{-1}$ corresponds to the symmetric and asymmetric stretching modes of $\mathrm{NH}_{2}$ group. The peak at $2920-2880 \mathrm{~cm}^{-1}$ with medium intensity refers $\mathrm{C}$-Hasymmetric stretching. Combinational overtones extend to the bands from 2420-2300 $\mathrm{cm}^{-1}$. The peak at $1750 \mathrm{~cm}^{-1}$ indicating the $\mathrm{C}=\mathrm{O}$ stretching mode of vibration. The $\mathrm{NH}_{2}$ bending vibrations occur at 1630,1622 and $785 \mathrm{~cm}^{-1}$. The peak at 1540 $\mathrm{cm}^{-1}$ is due to $\mathrm{NH}_{2}$ bending vibration. The peaks at $1490-1440 \mathrm{~cm}^{-1}$ corresponds to the $\mathrm{C}=\mathrm{S}$ stretching. The C-C stretching mode of vibration occurs in $1328 \mathrm{~cm}^{-1}$ peak. The peak at $1225 \mathrm{~cm}^{-1}$ gives rise to $\mathrm{C}-\mathrm{N}$ stretching mode of vibration. The spectra show absorption bands in the region of $1145 \mathrm{~cm}^{-1}$ and $1030 \mathrm{~cm}^{-1}$ which are due to in-plane C-H bending vibration. The band $1115 \mathrm{~cm}^{-1}$ signifies the $\mathrm{N}-\mathrm{H}$ symmetric bending. The bands at $857 \mathrm{~cm}^{-1}$ and $808 \mathrm{~cm}^{-1}$ revealed that $\mathrm{C}-\mathrm{N}$ deformation mode. The ring deformation occurs at $828 \mathrm{~cm}^{-1}$. $\mathrm{C}=\mathrm{O}$ deformation is identified by the band at $675 \mathrm{~cm}^{-1}$. C-H out-of plane bending peaks obtained at $660 \mathrm{~cm}^{-1}$ and $648 \mathrm{~cm}^{-1}$. The bands $645-638 \mathrm{~cm}^{-1}$ represents C-C deformation. The absorption bands in the region of $486-471 \mathrm{~cm}^{-1}$ are due to $\mathrm{N}-\mathrm{C}$ stretching vibration. The assignments confirm the presence of various functional groups present in the material. The absorption around $1600 \mathrm{~cm}^{-1}$ is $\mathrm{NH}_{2}$ bending and this band would be shifted into lower wavelength region $1638 \mathrm{~cm}^{-1}$. The absorption bands in the region of $920-810 \mathrm{~cm}^{-1}$ are due to the presence of aromatic ring. Our investigations were well compared with earlier reports ${ }^{10-19}$.

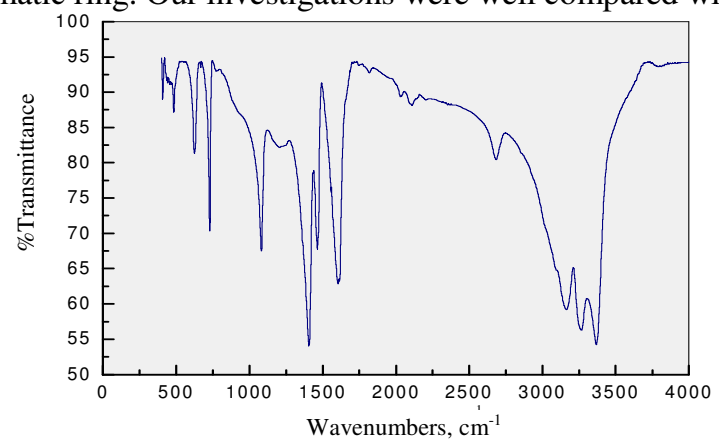

Figure 3. FT-IR spectrum of NiNTU

\section{UV-Visible studies}

The UV-Visible spectrum of the single crystal NiNTU indicates low and high absorption in the entire visible and near infrared region of the crystals. This is a desirable property for NLO applications since a wider optical transparency in these regions enhances the frequency conversion efficiency in the corresponding wavelengths (Table 2).

The cuts off wavelengths of NiNTU single crystal were found to be $480 \mathrm{~nm}, 866 \mathrm{~nm} 920$ $\mathrm{nm}, 974 \mathrm{~nm}$ and $1017 \mathrm{~nm}$ respectively. The presence of amino, imino, keto and thio carbonyl groups are confirmed by the peaks around 416, 480, 574 and $866 \mathrm{~nm}$ values. The presence of aromatic ring is confirmed by the cut of wavelength around $920,975,1017 \mathrm{~nm}$. The good optical transmittance in the entire visible region and the cut off wavelength $\left(\lambda_{\text {cut }}\right)$ was observed as this is due to $\pi-\pi *$ transition in the compounds. The band gap energy $\left(\mathrm{E}_{\mathrm{g}}=\mathrm{hc} / \lambda\right)$ was found to be $10.46 \mathrm{eV}$ for pure and NiNTU crystals. The large transmission in the entire visible region and short cut off wavelength enables it to be a potential material for second and third harmonic generation ${ }^{20-27}$. 
Table 2. Cuts off wavelengths of NiNTU single crystal

\begin{tabular}{ccc}
\hline Crystal & Wavelength, $\mathrm{nm}$ & \% Transmittance \\
\hline & 416 & 57.0 \\
& 480 & 57.1 \\
NiNTU & 574 & 59.2 \\
& 866 & 92.9 \\
& 920 & 91.9 \\
& 974 & 136.1 \\
& 1017 & 102.9 \\
\hline
\end{tabular}

\section{Nuclear magnetic resonance spectroscopy}

NMR spectrum of NiNTU was recorded using FT-NMR spectrometer. NiNTU crystal was powdered and dissolved in deuterated dimethyl sulfoxide (DMSO). FT-NMR spectrum recorded for NiNTU is shown in Figure 4. A chemical shiftsat 8.230, 8.024, 7.698 and 7.067 $\mathrm{ppm}$ are due to Ar-H in the form of bicyclic ring proton. The chemical shift at 7.047-7.716 ppm is assigned to $=\mathrm{C}-\mathrm{NH}-\mathrm{C}=$ proton. Chemical shift at $6.647-6.665 \mathrm{ppm}$ is due to $\mathrm{H}-\mathrm{N}-$ $\mathrm{C}=\mathrm{O}$. A chemical shift at $5.522-5.626 \mathrm{ppm}$ is due to naphthylamine proton ${ }^{12}$. The chemical shift at 7.323-7.7.406 is due to $\mathrm{H}-\mathrm{N}-\mathrm{C}=\mathrm{O}$. A chemical shift at 3.460 is due to $-\mathrm{C}=\mathrm{S}$. The above values confirm the structure of NiNTU.

\section{Thermal analysis}

TGA analysis of the NiNTU crystal was carried out in the temperature range $10-900{ }^{\circ} \mathrm{C}$. The recorded themogram is shown in Figure 5. From TGA curve it is observed that the weight loss start from $220^{\circ} \mathrm{C}$. There is $35.5 \%$ weight loss is due to the liberation of naphthylamine molecule at $240{ }^{\circ} \mathrm{C}$. There is $6.56 \%$ weight loss between $330{ }^{\circ} \mathrm{C}$ to $390{ }^{\circ} \mathrm{C}$. This weight loss is due to the liberation of $\mathrm{NH}_{3}$. There is $11.5 \%$ weight loss between $590^{\circ} \mathrm{C}$ to $670^{\circ} \mathrm{C}$. This weight loss is due to the liberation of $\mathrm{CO}$. There is $13.4 \%$ weight at $830^{\circ} \mathrm{C}$. This weight loss is due to the liberation of $\mathrm{H}_{2} \mathrm{~S}$. This endothermic event is in good agreement with the TGA trace ${ }^{21}$.

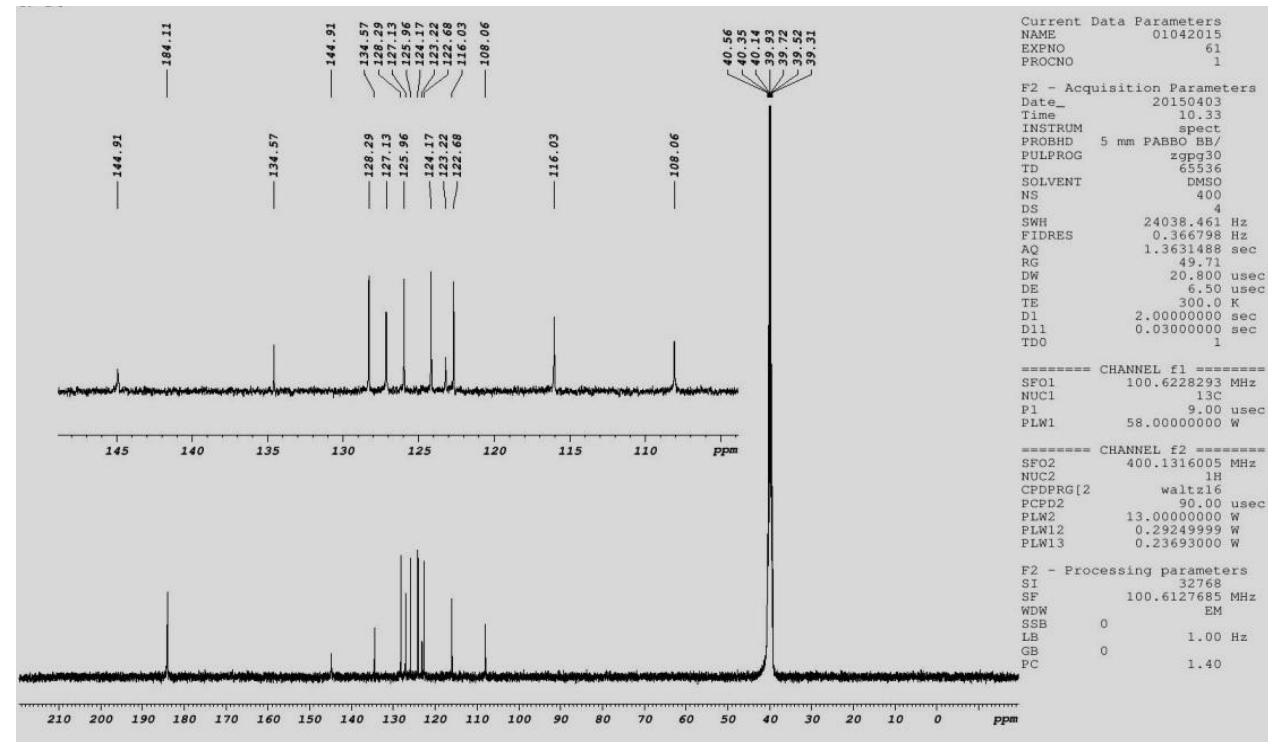

Figure 4. NMR spectrum of NiNTU 


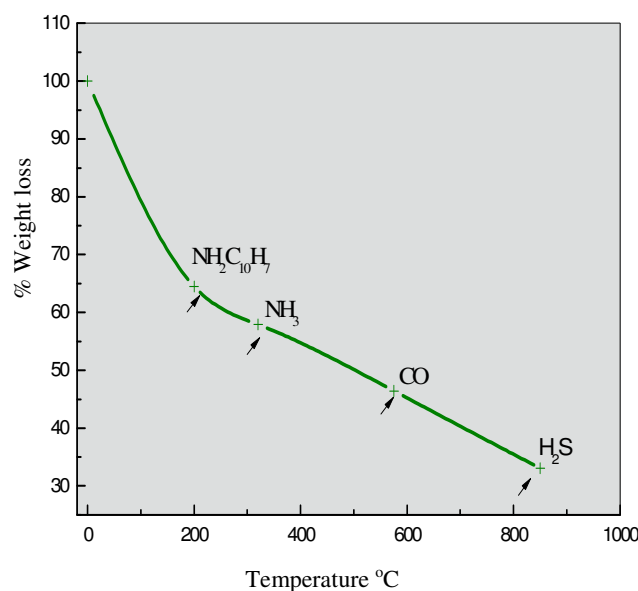

Figure 5. Thermogravimetric analysis for the determining the weight loss

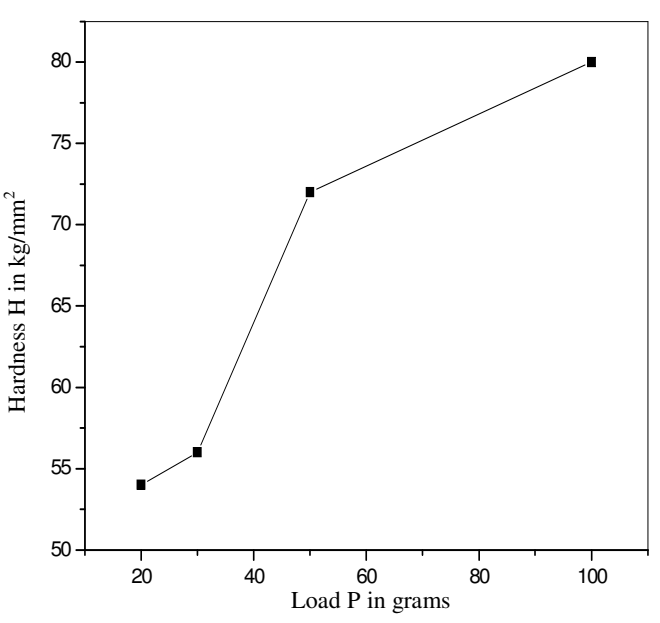

Figure 6. Variation hardness number with load

\section{Micro hardness studies}

Hardness of the material is a measure of resistance that offers to deformation. The transparent polished crystal free from cracks was selected for hardness measurements. The indentations were made on the flat surface with the load ranging from 10 to $100 \mathrm{~g}$ using Shimadzu make-model-HMV-2 fitted with Vicker's pyramidal indenter and attached to an incident light microscope. The indentation time was kept as $5 \mathrm{~s}$ for all the loads. The Vicker's hardness (Hv) was calculated from the relation ${ }^{21}$

$$
H v=\frac{1.8544 P}{d^{2}} P / d^{2} \mathrm{~kg} / \mathrm{mm}^{2}
$$

Where, $\mathrm{P}$ is the applied load and $\mathrm{d}$ the average length of the diagonal of the indentation mark. With $\mathrm{P}$ in $\mathrm{g}$ and $\mathrm{d}$ in $\mu \mathrm{m}$, the units of $\mathrm{Hv}$ turned out to be $\mathrm{kg} / \mathrm{mm}^{2}$. The variation of micro hardness with applied load for the prominent (102) plane of the NiNTU crystal is shown in Figure 6. It is found that the hardness values increases with the increase of the applied load. This behaviour of increasing micro hardness with the load known as reverse indentation size effect (RISE) ${ }^{21}$, which is also attributed due to existence of distorted zone near crystal medium interface, effect of vibrations, specimen chipping etc., and the plastic deformation is dominant. At low loads or strains, plastic deformation of crystals mainly involves the nucleation of dislocations along a particular slip system. The RISE effect can be qualitatively explained on the basis of the depth of penetration of the indenter ${ }^{21}$. At small loads, the indenter penetrates only the surface layers and therefore, the effect is shown sharply at the early stages. When the applied load increases, the penetration depth also increases and the overall effect must be due to the surface and inner layers. When only one slip system is active during plastic deformation at low loads, the number of active parallel glide planes during indentation is low. Therefore the nucleating dislocations rapidly propagate into the material without experiencing substantial mutual interaction stress between them. Consequently in this stage, indentation depth increases proportionally with applied pressure. 


\section{NLO studies}

The second harmonic signal, generated in the crystals was confirmed from the emission of orange radiation by the crystals. The NLO SHG values of the NiNTU single crystals were determined and compared to the reported SHG value of pure $\mathrm{KDP}^{21}$ is shown in Table 3.

Table 3. The NLO SHG value of pure KDP

\begin{tabular}{ccc}
\hline Crystal & $\begin{array}{c}\text { Second harmonic signal } \\
\text { output }(\mathrm{mJ})\end{array}$ & $\begin{array}{c}\text { SHG efficiency (compared to SHG } \\
\text { efficiency of pure KDP) }\end{array}$ \\
\hline NiNTU & 10.5 & 4.2 \\
\hline
\end{tabular}

\section{Conclusion}

The good quality single crystals of Nickel Naphthylamine Thiourea Urea single Crystal are successfully grown by slow evaporation method at room temperature.The UV-Visible spectra showed that the crystals had a wide optical window, no absorbance and good optical transmittance in the entire visible region. FT-IR analysis confirmed the presence of functional groups in the grown crystals. TGA thermogram revealed the thermal stability of the materials. The powder X-Ray diffraction study confirms the lattice parameter values. The good optical quality and their suitability for NLO applications. Kurtz-Perry powder SHG test was employed to determine the SHG efficiency of the samples and the values were compared to the reported SHG efficiency of pure KDP.

\section{References}

1. Saha J K and Podder J, J Bangladesh Academy of Sciences, 2011, 35(2), 203-210; DOI:10.3329/jbas.v35i2.9426

2. Viruthagiri G, Praveen P, Mugundan S and Anbuvannan M, Indian J Adv Chem Sci., 2013, 1(4), 193-200.

3. Sundararajan R S, Senthilkumar M and Ramachandraraja C, J Crystallization Process Technology, 2013, 3, 56-59; DOI:10.4236/jcpt.2013.32008

4. Gunasekaran S, Anand G, Arun Balaji R, Dhanalakshmi J and Kumaresan S, J Phys., 2010, 75(4), 683-690; DOI:10.1007/s12043-010-0148-y

5. Thomas Joseph Prakash J and Ruby Nirmala L, Inter J Compr Appl., 2011, 6, 0975-8887.

6. Duan X E, Wei X H, Tong H B, Bai S D, Yong B Z and Dian S L, J Mole Struct., 2011, 1005(1-3), 91-99; DOI:10.1016/j.molstruc.2011.08.030

7. KrishnaMoha M N, Jagannathan K, Ponnusamy S and Muthamizhchelvan C, J Phys Chem Solids, 2011, 72(11), 1273-1278; DOI:10.1016/j.jpcs.2011.07.020

8. Muthu K and Meenakashisundaram S P, J Crystal Growth, 2012, 352(1), 158-162; DOI:10.1016/j.jcrysgro.2012.01.024

9. Chandrasekaran J, Ilayabarathi P, Maadeswaran P, Mohamed Kutty P and Pari S, Optics Commun., 2012, 285(8), 2096-2100; DOI:10.1016/j.optcom.2011.12.063

10. Chandrasekaran J, Ilayabarathi P and Maadeswaran P, Rasayan J Chem., 2011, 4(2), 320-326.

11. Krishnakumar V and Nagalakshmi R, Spectrochimica Acta Part A: Molecular Biomolecular Spectroscopy, 2007, 68(3), 443-453; DOI:10.1016/j.saa.2006.11.049

12. Vijayan N and Ramesh Babu R, J Crystal Growth, 2004, 267(3-4), 646-653; DOI:10.1016/j.jcrysgro.2004.04.008

13. Mohankumar R and Rajanbabu D, Jayaramanc D, Jayaveld R and Kitamura K, $J$ Crystal Growth, 2005, 275(1-2), 1935-1939; DOI:10.1016/j.jcrysgro.2004.11.260 
14. Merry H O, Warren L F, Applied Optics, 1992, 31(24), 5051-5060; DOI:10.1364/AO.31.005051

15. Venkataraman V, Dhavaraj G and Bhat H L, J Crtys Growth, 1995, 154(1-2), 92-97; DOI:10.1016/0022-0248(95)00212-X

16. Hanna M C, Lu Z H, Cahill A F, Heben M J and Nozik A J, J Crystal growth, 1997, 174(3-4), 605-610; DOI:10.1016/S0022-0248(97)00029-8

17. $\mathrm{Cu}$ D, Jiaog M and Taus Z, Acta Chimica Sinica, 1983, 41(6), 570-573.

18. Ramachandraraja C and Sundararajan R S, SpectrochimicaActa Part A: Molecular Biomolecular Spectroscopy, 2008, 71(4), 2008, 1286-1289; DOI:10.1016/j.saa.2008.03.028

19. Kurtz S K and Perry T T, J Appl Phys., 1968, 39(8), 3798-3814; DOI:10.1063/1.1656857

20. Martin Britto Dhas S A, Suresh J, Bhagavannarayana G and Natarajan S, Open Crystallography J, 2008, 1, 46-50; DOI:10.2174/1874846500801010046

21. Ruby A and Alfred Cecil Raj S, International J Scientific Res Publications, 2013, 3(3), 1-5.

22. Lawrence G M and Thomas Joseph Prakash J, Spectrochimica Acta Part A, 2012, 91, 30-34; DOI:10.1016/j.saa.2012.01.055

23. Patel J D, Mighri F and Ajji A, Materials Letters, 2012, 74, 183-186; DOI:10.1016/j.matlet.2012.01.089

24. Patel J D, Mighri F, Ajji A and Chaudhurid T K, Mater Chem Phys., 2012, 132(2-3), 747-755; DOI:10.1016/j.matchemphys.2011.12.006

25. Anandan P, Jayavel R, Saravanan T, Parthipan G, Vedhi C and Mohan Kumar R, Optical Materials, 2012, 34(7), 1225-1230; DOI:10.1016/j.optmat.2012.01.042

26. Joema S E, Perumal S and Ramalingam S, Recent Res Technol., 2011, 3, 2076-5061.

27. Ramajothi J, Dhanuskodi S and Akkurt M, Spectrochimica Acta Part A, 2008, 69(4), 1271-1276; DOI:10.1016/j.saa.2007.07.019 